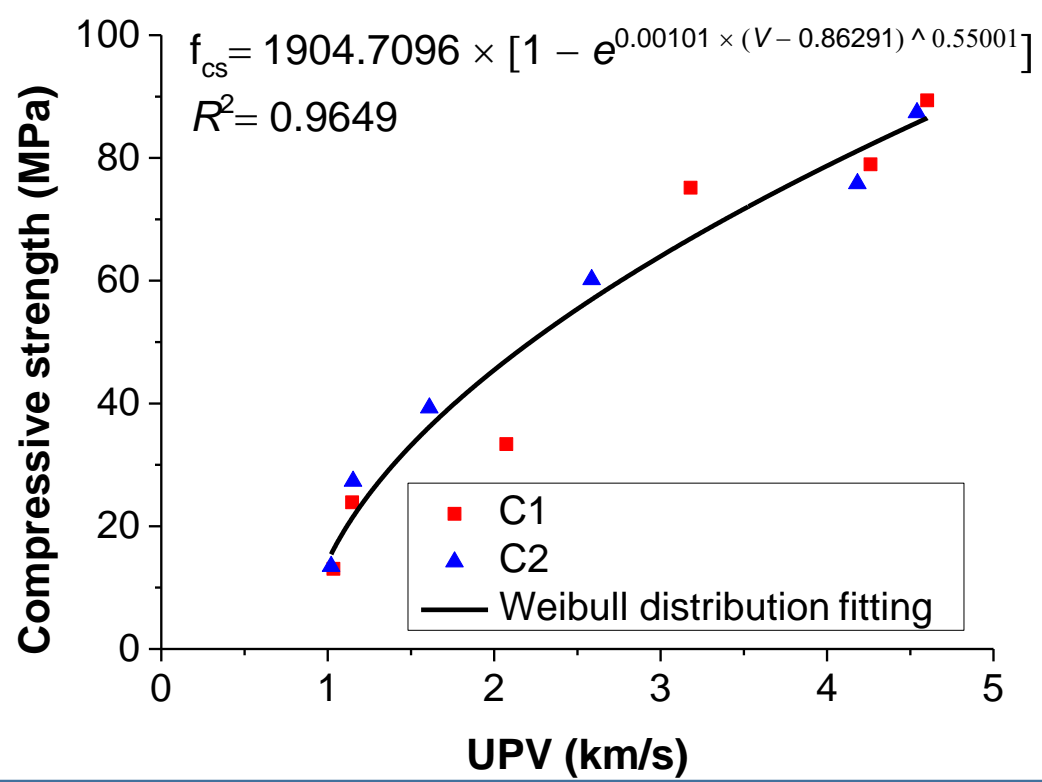

UPV: Ultrasonic pulse velocity

Porosity of FSCs

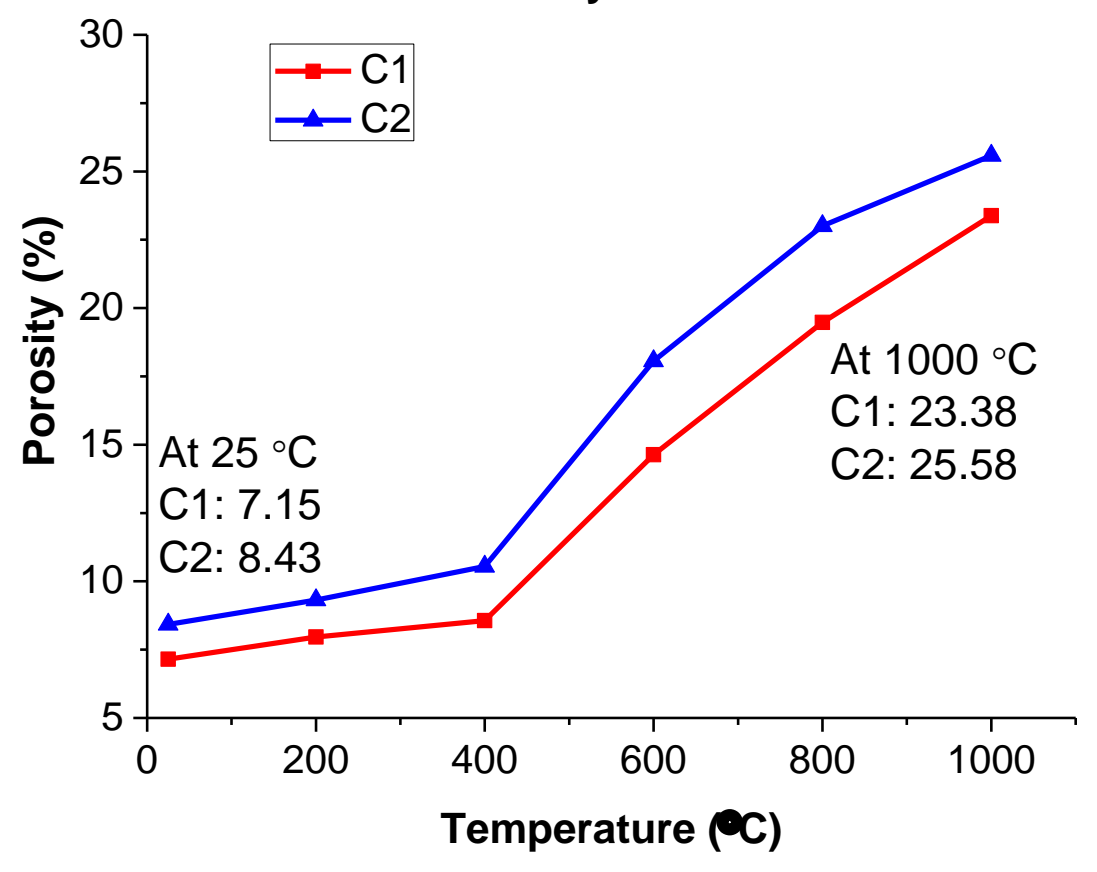

Relationship between splitting tensile strength and UPV

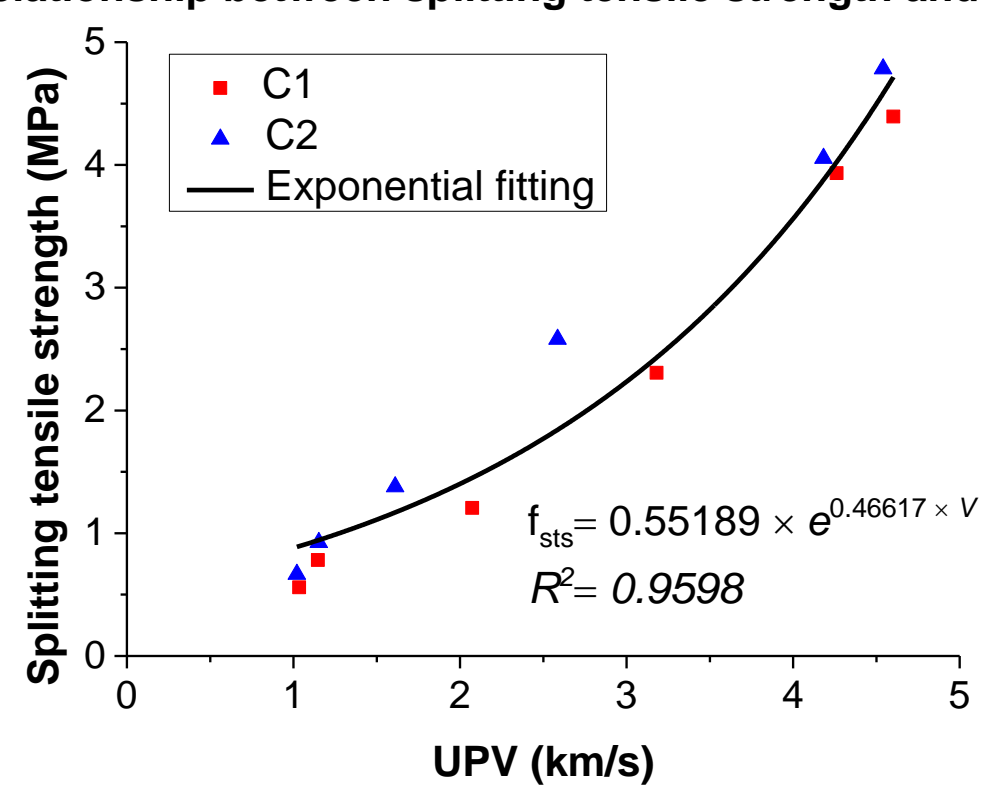

XRD patterns of FSC with PP fibers

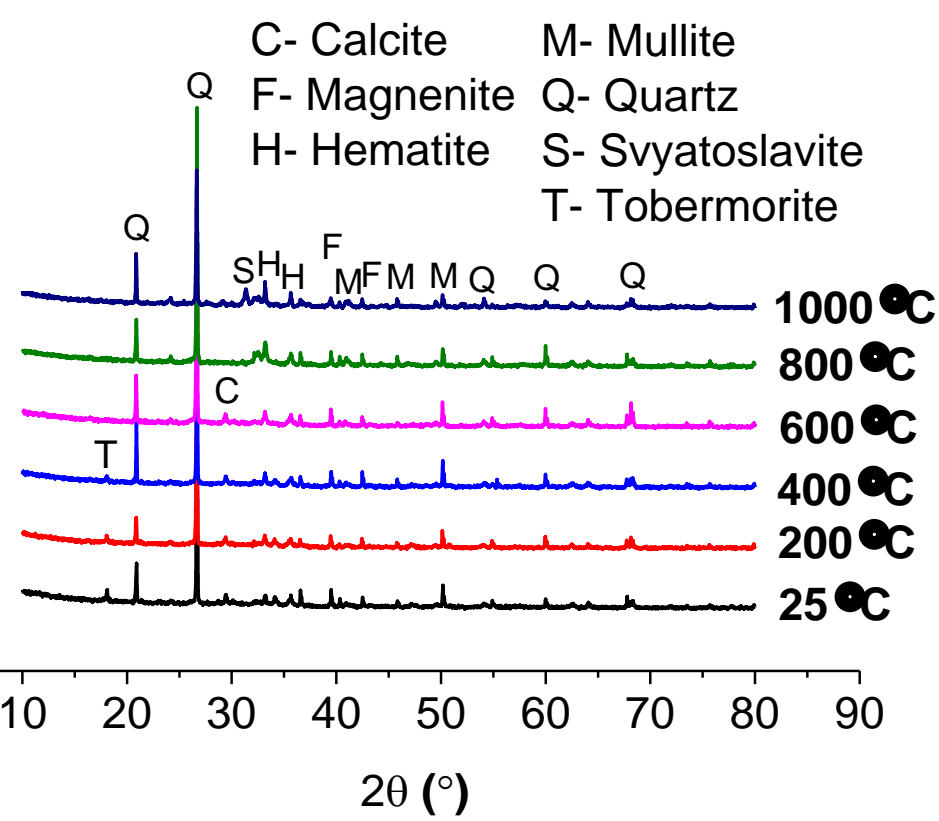

FSC: Ferro-siliceous concrete 


\section{Mechanical and physicochemical properties of ferro-siliceous concrete subjected to elevated}

\section{temperatures}

Hong-yan Chu ${ }^{a, b}$, Jin-yang Jiang ${ }^{a, b^{*}}$, Wei Sun ${ }^{a, b}$, Mingzhong Zhang ${ }^{c}$

${ }^{a}$ School of Materials Science and Engineering, Southeast University, Nanjing 211189, China

b Jiangsu Key Laboratory of Construction Materials, Nanjing 211189, China

${ }^{\mathrm{c}}$ Department of Civil, Environmental and Geomatic Engineering, University College London, London WC1E 6BT, UK

Abstract: Ferro-siliceous concrete (FSC), as a sacrificial material, is used in European Pressurized Water Reactor. This paper presents an experimental investigation on the performance of FSC with and without polypropylene (PP) fibers subjected to elevated temperatures. Mechanical and physicochemical properties of FSCs were studied at both ambient and high temperatures. The occurrence of spalling, compressive strength, splitting tensile strength, mass loss, porosity, chemical composition, crystalline phase, and thermal analysis of FSCs before and after exposure to various temperatures $\left(200,400,600,800\right.$, and $\left.1000{ }^{\circ} \mathrm{C}\right)$ were comprehensively investigated. Ultrasonic pulse velocity (UPV) propagation in FSCs at different temperatures was determined by ultrasonic testing technique, and the relationships between strengths and UPV of FSCs were eventually obtained. The results indicated that, (1) the critical temperature range of FSCs was $400-600{ }^{\circ} \mathrm{C}$; (2) the compressive strength-UPV and splitting tensile strength-UPV relationships were Weibull distribution and exponential form, respectively; (3) compared to unheated FSCs, the porosity values were more than trebled after exposure to $1000^{\circ} \mathrm{C}$.

Key words: concrete; compressive strength; splitting tensile strength; high temperature; porosity;

* Corresponding author. Tel.: +86-025-52090667; E-mail address: jiangjinyang16@ 163.com (J.-y. Jiang) 
thermal analysis; ultrasonic pulse velocity

\section{Introduction}

Ferro-siliceous concrete (FSC) is a key component of European Pressurized Water Reactor which is the typical representative of the third generation nuclear technique. The significant innovations of this technique are severe accident mitigation and security improvements of nuclear power plant by utilization of FSC [1]. For the convenience of construction, FSC has high flowability and deformability, so it can be called self-consolidating concrete (SCC). Moreover, its $28 \mathrm{~d}$ compressive strength is higher than $80 \mathrm{MPa}$, thus it can be termed as high strength concrete (HSC) in this sense. Due to its special service environment, the behavior of FSC subjected to elevated temperatures has in particular to be evaluated. In addition, its coarse and fine aggregates are greatly different from normal strength concrete (NSC), which may result in material properties distinctions between these 2 kinds of concretes when exposed to high temperatures.

In case of fire or severe nuclear accident, concrete is subjected to elevated temperature that induces dramatic physical and chemical changes, leading to material deterioration: strength and stiffness decrease [2], cracking, and in certain circumstances spalling can occur [3]. Up to now, the effect of high temperatures on NSC and HSC has been studied extensively. The behavior of NSC under elevated temperatures has been clearly understood according to the results of researches carried out since 1950s $[4,5]$. In recent years, there have been numerous studies on the thermal behavior of HSC and on the differences between HSC and NSC. The investigation on the behavior of concrete subjected to elevated temperatures by Phan and Carino [6] has indicated that the rate of strength loss is different between NSC and HSC. Poon et at. [7] carried out a comprehensive research on the behavior of 3 series of HSCs with different cementitious material constitutions. The 
results suggested that after the HSCs exposure to high temperatures, the loss of stiffness is far quicker than that of compressive strength. Behnood and Ghandehari [8] have concluded that the range of $300-600{ }^{\circ} \mathrm{C}$ is more critical for HSC than NSC. They also found that the splitting tensile strength of concrete is more sensitive to elevated temperatures than the compressive strength. Xiao and Falkner [9] have pointed that the residual compressive strength of HSCs is decreasing sharply at $400{ }^{\circ} \mathrm{C}$. In addition, finding a relationship between the strength and ultrasonic pulse velocity (UPV) for concretes or structures subjected to high temperatures can provide a convenient method to assess concrete or structural damage in terms of strength.

Although the strength, workability, and durability of HSC are usually much superior to NSC at ambient temperature [10], its failure is sometimes rapid and dramatic when subject to elevated temperatures, characterized by spalling [11]. Many researches have confirmed that HSC is more prone to spalling than NSC when exposed to high temperature [12-15]. However, some inconsistent results have been reported concerning the characteristics of spalling, in which different critical temperatures for appearance of this phenomenon have been reported. Also, 3 different failure mechanisms have been put forward as the possible causes for spalling of HSC. The first theory that called bulid-up theory [16, 17] goes back to 1990s. The second mechanism of spalling is described by the thermal stress theory [18]. The third theory is a combination of the above 2 mechanisms, which is proposed by Bazant and Kaplan [3]. Now, the addition of polypropylene (PP) fibers to concrete is an effective method to reduce and even eliminate the spalling of HSC subjected to high temperatures, which has been recommended by many researchers [19-21]. PP fibers contribute to the pore pressure release, and limit the formation of thermal stress [18] resulting from an increase of concrete permeability through their melting at approximately $170{ }^{\circ} \mathrm{C}$. 
Currently, SCC, as a new building material with various excellent properties, has been widely applied in modern concrete structures, while scarce investigation results have been reported as to properties of SCC subjected to high temperatures. Based on the experimental research, Liu et al. [22] have concluded that the addition of PP fibers can reduce the thermal damage of self-compacting cement paste. A research on the microstructural changes of self-compacting cement paste subjected to high temperatures by Ye et al. [23] has indicated that its porosity shows a bigger change than that of high strength cement paste. An experimental investigation on the performance of SCC exposed to elevated temperatures conducted by Uysal [24] has concluded that a dramatic compressive strength loss is observed for SCC after subjecting to above $400{ }^{\circ} \mathrm{C}$. Fares et al. [25] have carried out a research on the properties of SCC exposed to elevated temperatures, and the findings demonstrated that the mechanical and physical properties of SCC decrease dramatically after heating up to $300{ }^{\circ} \mathrm{C}$. But, the behavior of FSC having characteristics of both HSC and SCC is not well understood when it subjects to elevated temperatures. In addition, there is no published investigation on the correlation between strength and UPV of FSC exposed to high temperatures.

The objective of this study is to analyze the mechanical and physicochemical properties of FSC with and without PP fibers subjected to elevated temperatures, and establish 2 relationships between strengths and UPV of FSCs. To this end, the occurrence of spalling, compressive strength, splitting tensile strength, mass loss, porosity, chemical composition, crystalline phase, and thermal analysis of FSCs before and after exposure to different high temperatures up to $1000{ }^{\circ} \mathrm{C}$ were comprehensively investigated. Per ultrasonic testing technique, UPV propagation in FSCs at different temperatures was determined, and the relationships between strengths and UPV of FSCs were eventually obtained. 


\section{Materials}

\subsection{Cement and mineral admixture}

Table 1 presents the chemical composition of the cement and mineral admixture used. Density, specific surface, and $28 \mathrm{~d}$ compressive strength of cement were $3150 \mathrm{~kg} / \mathrm{m}^{3}, 362.20 \mathrm{~m}^{2} / \mathrm{kg}$, and 62.80 MPa, respectively. Fly ash and silica fume were used as mineral addition in the experiment.

Moreover, all indexes of the fly ash can meet Class I according to the Chinese standard GB/T $1596-2005$, and the specific surface of the silica fume was $2.72 \times 10^{4} \mathrm{~m}^{2} / \mathrm{kg}$.

\subsection{Aggregate}

The fine and coarse aggregates were composed of quartz and iron ore, which were obtained from Nuclear Science and Technology (Tongchang) Co., Ltd. Notes that the quartz contained 2 ranges, namely, $0-5 \mathrm{~mm}$ and $5-8 \mathrm{~mm}$, and the content of them were $56 \mathrm{wt} . \%$ and $44 \mathrm{wt} . \%$, respectively. Similar to the quartz, there were also 2 ranges in the iron ore, that is, $0-4 \mathrm{~mm}$ and $4-8 \mathrm{~mm}$, whose weight percentage were $78 \%$ and $22 \%$, respectively. The particle size distribution of the aggregates is shown in Table 2.

\subsection{Superplasticizer}

A superplasticizer of polycarboxylate obtained from local supplier was employed to gain a satisfactory fluidity of FSCs. Water-reducing rate, air content, and density of the superplasticizer were, $33.9 \%, 3.8 \%$, and $1050 \mathrm{~kg} / \mathrm{m}^{3}$ at $20^{\circ} \mathrm{C}$, respectively.

\subsection{Polypropylene fiber}

The characteristics of PP fibers utilized in this research are presented in Table 3.

\subsection{Mixture proportion}

The 2 FSCs mixes investigated in the paper are given in detail in Table 4. 
According to the above mixture proportions, the specimens (shape: cubic; size: $100 \times 100 \times 100$ $\mathrm{mm}$ ) of FSCs were cast. After casting, the molds were covered with tinfoil papers, and cured $24 \mathrm{~h}$ at ambient condition, after which point the molds were removed, and the specimens were placed into concrete standard curing room for curing over a span of $28 \mathrm{~d}$ with a temperature range of $21 \pm 1{ }^{\circ} \mathrm{C}$ and relative humidity of above $95 \% .60$ cubic specimens were prepared for each mix.

\section{Experimental methodology}

\subsection{Elevated temperature test}

A computer-controlled radiant electrically furnace was applied to heating specimens from ambient temperature $\left(25^{\circ} \mathrm{C}\right)$ to $200,400,600,800$, and $1000{ }^{\circ} \mathrm{C}$, respectively, at an average heating rate of $5^{\circ} \mathrm{C} / \mathrm{min}$. According to literature [26], the specimens were held at the target temperature for $2 \mathrm{~h}$ so as to ensure uniform temperature throughout each specimen. After that, the furnace was turned off, and the specimens were cooled to ambient temperature in it. Note that the moisture in the tested specimens was allowed to escape freely from the furnace during the heating process.

For each mixture, 9 cubic $(100 \times 100 \times 100 \mathrm{~mm})$ specimens were placed in the furnace at each target temperature. All the specimens stored in the furnace were in the same condition so as to have a uniform temperature. The layout of the furnace with the specimens is shown in Fig. 1.

\subsection{UPV test}

The experiment on UPV was carried out according to literature [27].

\subsection{Mechanical tests}

\subsubsection{Compressive strength}

A universal testing machine was used to determine the compressive strength of specimens before and after heating to target temperatures of each mixture. According to the Chinese standard GB/T 
$50081-2002$, the loading rate was set as $0.80 \mathrm{MPa} / \mathrm{s}(0.80-1.00 \mathrm{MPa} / \mathrm{s})$ in the compressive strength

test.

\subsubsection{Splitting tensile strength}

The splitting tensile strength of each mix at ambient and each target temperature was determined by the universal testing machine equipped with a splitting tensile setup at a loading rate of 0.08 $\mathrm{MPa} / \mathrm{s}$.

\subsection{Physical and chemical properties}

\subsubsection{Mass loss}

The mass of each mixture was measured at ambient and each target temperature by 3 cubic specimens (about $25 \times 25 \times 25 \mathrm{~mm}$ ) split from $100 \times 100 \times 100 \mathrm{~mm}$ specimens. Notes that those specimens were heated from ambient temperature $\left(25^{\circ} \mathrm{C}\right)$ to $200,400,600,800$, and $1000{ }^{\circ} \mathrm{C}$ in turn at an average heating rate of $5{ }^{\circ} \mathrm{C} / \mathrm{min}$, and they were placed in the furnace immediately after weighing in order to avoid absorbing moisture in the air. In this way, the mass loss of each mix could be determined.

\subsubsection{Porosity}

Porosity and pore size distribution of different mixtures at ambient and each target temperature were analyzed by mercury intrusion porosimetry (MIP) measurement.

\subsubsection{Chemical composition}

The chemical and elemental composition of mortar of C2 mixture was determined by X-ray fluorescence (XRF) technique. Considering that the only difference between the 2 mixtures is the PP fibers which should have a meaningless effect on the chemical composition of FSCs, the experiment was only performed on $\mathrm{C} 2$ mix. 


\subsubsection{X-ray diffraction (XRD)}

The crystalline phase of FSC was determined by XRD. XRD was performed by using a Bruker D8-Discover diffractometer. The specimens were scanned between $10^{\circ}$ and $80^{\circ}(2 \theta)$. Similar to XRF, the XRD was also just performed on C2 mixture.

\subsubsection{Thermal analysis}

Thermal analysis of FSCs was carried out by differential scanning calorimetry (DSC) and thermogravimetric analysis (TGA), which was performed using a simultaneous thermal analyzer. The testing conditions were as follows: heating rate $10{ }^{\circ} \mathrm{C} / \mathrm{min}$, up to $1000{ }^{\circ} \mathrm{C}$, in nitrogen circumstance, at standard atmospheric pressure.

It should be pointed out that 3 replicate measurements were tested at each target temperature on the UPV, compressive strength, splitting tensile strength, and XRF experiments, and only the average values were reported in order to improve the accuracy of experimental results. In addition, all the specimens used in the XRF, XRD and thermal analysis experiments were ground by hand to a particle size of below $80 \mu \mathrm{m}$ using an agate mortar.

\section{Results and discussion}

\subsection{Occurrence of spalling}

Of the 2 types of FSCs subjected to elevated temperatures, only 1 of the specimens without PP fibers suffered spalling at about $900{ }^{\circ} \mathrm{C}$, which could be concluded that the addition of PP fibers can prevent FSC from spalling. However, the phenomenon could not be explained by the 3 spalling mechanisms mentioned in introduction. Because those mechanisms are depending crucially on the moisture distribution and the formation of moisture clog under high temperatures [16-18], while there is no moisture contained in the specimens at such high temperature $\left(900{ }^{\circ} \mathrm{C}\right)$. Thus, the 
spalling mechanism of FSC without PP fibers may be due to thermal damage, inner expansion force of closed voids, and incompatible deformation between aggregates and cement paste, so unlike the spalling mechanisms of NSC, HSC, and SCC, which requires further investigation. Fig.2 presents the specimens before and after high temperatures treatment.

\subsection{Residual compressive strength}

The residual compressive strength and the relative residual compressive strength of FSCs at ambient and after heating to high temperatures are shown in Fig.3. The relative residual compressive strength defines as the ratio of residual compressive strength at high temperature to compressive strength at ambient temperature.

As illustrated in Fig.3a, the compressive strength of FSC with and without PP fibers decreased continually with the increase of temperature, which is consistent with the results of HSC with PP fibers subjected to high temperatures [28]. The residual compressive strengths of FSC without fibers were higher than those of FSC with fibers during $25-400{ }^{\circ} \mathrm{C}$, while a contrary tendency was presented in $600-1000{ }^{\circ} \mathrm{C}$. In the range of $600-1000{ }^{\circ} \mathrm{C}$, the results obtained in this study are similar to literatures $[8,9,11]$, though the highest temperature is $900{ }^{\circ} \mathrm{C}$ in these literatures.

The compressive strength of FSC without PP fibers was higher than that of FSC with PP fibers at ambient temperature $\left(25^{\circ} \mathrm{C}\right)$, because the multifilament structure [8] forms in the FSC owing to the insufficient dispersing of PP fibers, which results in the increase of local porosity and then leading to decrease of compressive strength. In the range of $200-400{ }^{\circ} \mathrm{C}$, PP fibers are in molten state, but they are still in fiber morphology [22], so the addition of them cannot reduce thermal damage of FSC effectively, which causes the degradation of compressive strength of FSC with and without fibers in the same degree. Therefore, the compressive strength of FSC without PP fibers was higher 
than that of FSC with PP fibers in $200-400{ }^{\circ} \mathrm{C}$. PP fibers are vaporized in the range of $600-1000$ ${ }^{\circ} \mathrm{C}$, and the vaporized fibers can increase the porosity, and create additional pores and escape channels. Furthermore, the disappearance of PP fibers may decrease the thermal incompatibility between aggregates and cement paste owing to more free space. Hence, the thermal damage of FSC can be decreased effectively in these ways. Accordingly, the compressive strength of FSC without PP fibers was lower than that of FSC with PP fibers during $600-1000{ }^{\circ} \mathrm{C}$.

As shown in Fig.3b, the changing trends of relative residual compressive strength of FSC with and without PP fibers were accordant with those of residual compressive strength of FSCs. The relative residual compressive strengths of FSC with and without PP fibers did not change significantly at $200{ }^{\circ} \mathrm{C}$, at which the relative residual compressive strengths of FSCs were $88.33 \%$ (C1) and $86.77 \%(\mathrm{C} 2)$. However, they dropped drastically in the range of $400-600{ }^{\circ} \mathrm{C}$. The relative residual compressive strengths of them were only $37.35 \%(\mathrm{C} 1)$ and $44.98 \%(\mathrm{C} 2)$ at $600{ }^{\circ} \mathrm{C}$. Moreover, they decreased slowly during $800-1000{ }^{\circ} \mathrm{C}$, but their relative residual compressive strengths were merely $14.61 \%(\mathrm{C} 1)$ and $15.43 \%(\mathrm{C} 2)$ at $1000{ }^{\circ} \mathrm{C}$. Consequently, the critical temperature range of FSCs was $400-600{ }^{\circ} \mathrm{C}$, in which their compressive strength decreased drastically.

\subsection{Residual splitting tensile strength}

Fig. 4 illustrates the residual splitting tensile strength and the relative residual splitting tensile strength of FSCs at ambient and after heating to $200,400,600,800$, and $1000{ }^{\circ} \mathrm{C}$. Note that the relative residual splitting tensile strength is defined as the ratio of residual splitting tensile strength at elevated temperature to splitting tensile strength at ambient temperature.

With temperature increasing, the residual splitting tensile strength of FSCs was monotonically 
decreased as shown in Fig. 4a. Previous investigation [8] on HSC with and without PP fibers indicates the similar trends. In the whole range of $25-1000{ }^{\circ} \mathrm{C}$, the residual splitting tensile strengths of FSC without PP fibers were lower than those of FSC with PP fibers.

At ambient temperature $\left(25^{\circ} \mathrm{C}\right)$, the addition of PP fibers can introduce an increased resistance to crack growth for concrete materials [29], so the splitting tensile strength of FSC without PP fibers was lower than that of FSC with PP fibers. In this study, the splitting tensile strength of FSC with PP fibers was $8.87 \%$ higher than that of FSC without PP fibers at $25^{\circ} \mathrm{C}$. In addition, the reasons for variations of residual splitting tensile strengths of FSCs during $200-1000{ }^{\circ} \mathrm{C}$ are similar to those of their residual compressive strengths in the same temperature range.

As illustrated in Fig. 4b, the relative residual splitting tensile strengths of FSCs were decreased continually with the rise of temperature. The relative residual splitting tensile strength of FSC with PP fibers was higher than that of FSC without PP fibers at $200{ }^{\circ} \mathrm{C}$, while the opposite results were observed in the range of $400-1000{ }^{\circ} \mathrm{C}$. The relative residual splitting tensile strengths of FSC with and without PP fibers dropped slightly to $89.52 \%(\mathrm{C} 1)$ and $84.75 \%(\mathrm{C} 2)$ at $200{ }^{\circ} \mathrm{C}$. However, they decreased sharply in the range of $400-600{ }^{\circ} \mathrm{C}$ with a magnitude of $27.43 \%$ (C1) and $28.84 \%$ (C2) at $600{ }^{\circ} \mathrm{C}$. In addition, they declined slowly during $800-1000{ }^{\circ} \mathrm{C}$, but their relative residual splitting tensile strengths were barely $12.74 \%(\mathrm{C} 1)$ and $13.93 \%(\mathrm{C} 2)$ at $1000{ }^{\circ} \mathrm{C}$. Thus, the range $400-600{ }^{\circ} \mathrm{C}$ could also be considered the critical temperature range for splitting tensile strength loss of FSCs.

Furthermore, a comparative investigation on the relative mechanical properties of 2 FSCs was carried out. Table 5 presents the relative compressive strength and relative splitting tensile strength of FSCs at ambient $\left(25^{\circ} \mathrm{C}\right)$ and after heating to $200,400,600,800$, and $1000^{\circ} \mathrm{C}$. 
As shown in Table 5, the relative residual compressive strengths of FSCs were higher than those of their relative residual splitting tensile strengths in the range of $200-1000{ }^{\circ} \mathrm{C}$, except for $\mathrm{C} 1 \mathrm{mix}$ at $200{ }^{\circ} \mathrm{C}$. In particular, the former were $60.22 \%(\mathrm{C} 1)$ and $22.70 \%(\mathrm{C} 2)$ higher than the latter at 400 ${ }^{\circ} \mathrm{C}$, respectively. Therefore, the elevated temperature has a more severe effect on the splitting tensile strength of FSCs than that of the compressive strength. On one hand, the cracks are prone to open under tensile loading, while they are prone to close up subjected to compressive loading. Thus, the impact of crack coalescence is more crucial on the splitting tensile strength than that on the compressive strength of FSCs. On the other hand, the increasing temperature has a significant influence on the crack propagation and the localization of micro-cracks into macro-cracks caused by the moisture clog [30], decomposition of the hydration products, and incompatible thermal deformation between aggregates and cement paste.

\subsection{UPV} presented in Fig.5.

As shown in Fig.5, the UPV of FSCs decreased continually with the increase of temperature, which is in line with the results of reference [14]. This phenomenon corresponded with the changing trends of the compressive strength (Fig.3a) and splitting tensile strength (Fig.4a), the result of which indicated that the deterioration of FSCs could be evaluated by the means of UPV test. There was an accelerating process in the decrease of UPV of FSCs in the range of $200-800{ }^{\circ} \mathrm{C}$, and the UPV of FSC with and without PP fibers at $1000{ }^{\circ} \mathrm{C}$ was $1.04 \mathrm{~km} / \mathrm{s}$ and $1.02 \mathrm{~km} / \mathrm{s}$, respectively. The decrease of UPV with the increase of temperature is due to the damaged microstructure and the induced thermal damage in concrete [31]. 
The UPV of FSC without PP fibers was always higher than that of FSC with PP fibers in the

whole range of $25-1000{ }^{\circ} \mathrm{C}$. At ambient temperature, the increase of local porosity [8] results from the insufficient dispersing of PP fibers, which leads to the decrease of UPV propagation in FSC with PP fibers. At elevated temperatures, the PP fibers in concrete have double effects on the UPV. As for accelerating effect, channels left by molten PP fibers are helpful to reduce the thermal damage, which finally results in the increase of the UPV. However, decelerating effect means that channels caused by molten PP fibers themselves are material defects (damage) due to high temperature, which leads to the UPV drop. In the range of $200-1000{ }^{\circ} \mathrm{C}$, the reason for the phenomenon can be attributed to that the decelerating effect of PP fibers outweighs their accelerating effect.

\subsection{Relationships between strengths and UPV}

The relationships between strengths and UPV for FSCs before and after exposure to elevated temperatures are shown in Fig.6.

As illustrated in Fig.6a, with the increase of UPV, the compressive strength of FSCs increased monotonically, and the compressive strength evolution of them was consistent, the result of which could be described by a Weibull distribution model, as the full cure in Fig.6a. The equation of the Weibull distribution model was shown as follows,

$$
f_{C S}=1904.7096 \times\left[1-e^{0.00101 \times(V-0.86291)^{0.55001}}\right]
$$

where $f_{c s}$ is the compressive strength of FSCs, and $V$ is the UPV propagation in FSCs.

As shown in Fig.6b, the splitting tensile strength of FSC with and without PP fibers increased continually with the increase of UPV, and the splitting tensile strength evolution of them was accordant. The results indicated that an exponential relationship provided an approximation to 
evaluate the splitting tensile strength of FSCs through UPV. The following was the relationship,

$$
f_{\text {sts }}=0.55189 \times e^{0.46617 \times V}
$$

where $f_{\text {sts }}$ is the splitting tensile strength of FSCs.

The $R$-Square of the Weibull distribution and exponential fitting was 0.9649 and 0.9598 , respectively, which suggested that the fitting results matched rather well with the experimental data, and that Eqs. (1) and (2) could be used to assess the compressive strength and the splitting tensile strength of FSCs by UPV.

It should be noted that the empirical formulas may not precisely assess the strengths (both compressive and splitting tensile strength) of FSCs with different compositions (e.g. different aggregate types). On the whole, however, the models established in the study were reasonably accurately to evaluate the strengths of FSCs subjected to elevated temperatures. In practice, the established models can provide a convenient method to assess concrete or structural damage in terms of strengths in case of fire hazard, engulfment by lava flow, or nuclear accident.

\subsection{Mass loss}

Fig.7 presents the mass loss evolutions of FSC with and without PP fibers obtained from cubic specimens (about $25 \times 25 \times 25 \mathrm{~mm}$ ) after exposure to high temperatures. Note that ratio of mass loss equals to the mass loss divided by its initial mass.

It was observed that the evolution of mass loss as a function of temperature was very close for the 2 FSCs. Between ambient temperature and $200{ }^{\circ} \mathrm{C}$, the variation of mass was significantly corresponding to more than half of the total mass loss. Between 200 and $800{ }^{\circ} \mathrm{C}$, a moderate variation was observed for 2 FSCs. However, the variation of mass was rather weak during $800-$ $1000{ }^{\circ} \mathrm{C}$. These results are similar with published data of [23], in which the evolution of mass loss 
versus temperature is also very close for the $2 \mathrm{SCC}$, although the maximum temperature is $600{ }^{\circ} \mathrm{C}$ in the study.

As illustrated in Fig. 7, the mass loss of the FSC without PP fibers was slightly higher than that of the FSC with PP fibers in the range of $200-600^{\circ} \mathrm{C}$. However, the mass loss of them was nearly the same during $800-1000{ }^{\circ} \mathrm{C}$ with a magnitude of $7.07 \%(\mathrm{C} 1)$ and $7.09 \%(\mathrm{C} 2)$ at $1000{ }^{\circ} \mathrm{C}$.

The initial water contents in the 2 mixtures were the same. So, as the heating rate was moderate $\left(5{ }^{\circ} \mathrm{C} / \mathrm{min}\right.$ ), and in spite of the fact that the porosity and permeability of FSCs were different due to the addition of PP fibers, water or moisture could have time to escape from the FSCs independent of their composition. The mass loss for the 2 FSCs s was therefore very similar.

\subsection{Porosity}

The porosity and pore size distribution of FSCs at ambient temperature $\left(25^{\circ} \mathrm{C}\right)$ and after heating to $200,400,600,800$, and $1000{ }^{\circ} \mathrm{C}$ are presented in Fig. 8, respectively.

As shown in Fig. 8a, with temperature increasing, a monotonous increase of porosity for FSC with and without PP fibers was observed. In the range of $25-400{ }^{\circ} \mathrm{C}$, the porosity increased gradually for the two FSCs with a magnitude of $19.70 \%$ (C1) and $23.82 \%$ (C2), which could explain the slight decrease of the compressive strength and the splitting tensile strength of these concretes during this temperature range. However, a sharp increase in porosity was observed after heating to $600{ }^{\circ} \mathrm{C}$, confirming a severe material deterioration that can have an impact on the mechanical properties of FSCs. In particular, with reference to unheated FSCs, the porosity values were more than trebled after exposure to $1000^{\circ} \mathrm{C}$.

The porosity of FSC without PP fibers was lower than that of FSC with PP fibers in the whole range of $25-1000{ }^{\circ} \mathrm{C}$, as illustrated in Fig. 8a. However, no big difference could be observed for 
the porosity of FSC with and without PP fibers at ambient temperature and each target temperature, which is consistent with the observation by Liu et al. [22].

As to pore size distribution, there were multi peaks during $25-1000{ }^{\circ} \mathrm{C}$, and the critical pore diameter increased with the increase of temperature (Fig.8b, c). In $\mathrm{C} 1$ mixture (Fig.8b), most of the pores size at 25,400 , and $1000{ }^{\circ} \mathrm{C}$ were within two peaks interval $(0.004310,0.02460),(0.005934$, $0.9822)$, and $(0.5388,27.32)$ respectively, all in $\mu \mathrm{m}$. A similar trend was observed in $\mathrm{C} 2$ mixture (Fig.8c), but to a larger degree, from $0.02627-0.05296 \mu \mathrm{m}$ at $25^{\circ} \mathrm{C}$, to $0.07706-2.081 \mu \mathrm{m}$ at $400{ }^{\circ} \mathrm{C}$, to $0.4633-30.22 \mu \mathrm{m}$ at $1000{ }^{\circ} \mathrm{C}$. These results could justify that the porosity of FSCs increased slowly in the range of $25-400{ }^{\circ} \mathrm{C}$, while the porosity increased rapidly after heating to $400{ }^{\circ} \mathrm{C}$.

Kalifa et al. [20] attribute the increase in porosity with temperature to the escape of bound water and to the micro-cracks generated by incompatible expansion between the aggregates and cement paste. In addition, Fares et al. [25] point out the evolution of porosity of concrete subjected to high temperature due to the departure of absorbed water in capillary pores and the release of bound water in the hydration products of cement paste. The research carried out by Ye et al. [23] indicates that the increase in porosity of concrete subjected to high temperatures is due to the decomposition of $\mathrm{C}-\mathrm{S}-\mathrm{H}$ and $\mathrm{CH}$. Many micro-cracks and decomposition of hydration products at $600{ }^{\circ} \mathrm{C}$ were observed in the study, as shown in Fig. 9, which could be related to the evolution of porosity of FSCs.

\subsection{Chemical composition}

The chemical and elemental compositions of mortar of C2 mixture is shown in Table 6.

As shown in Table 6, the content of hematite $\left(\mathrm{Fe}_{2} \mathrm{O}_{3}\right)$ was 14.08 wt.\%, which is different from 
ordinary concretes [32]. The content of $\mathrm{SiO}_{2}$ in $\mathrm{FSC}$ was slightly lower than that of hematite-containing concrete used in VULCANO experiment [32], while the content of $\mathrm{Fe}_{2} \mathrm{O}_{3}$ in the former was higher than that of the latter, which indicated that the content of key chemical composition $\left(\mathrm{SiO}_{2}\right.$ and $\left.\mathrm{Fe}_{2} \mathrm{O}_{3}\right)$ of $\mathrm{FSC}$ is similar to hematite-containing concrete used in VULCANO experiment. In addition, the elemental compositions of FSC contributed to analyze crystalline phase of the concrete.

\subsection{XRD}

The XRD patterns of mortar of C2 mixture at ambient and different elevated temperatures are presented in Fig. 10.

The main crystalline phases of mortar of $\mathrm{C} 2$ mixture at ambient temperature were tobermorite, calcite, quartz, hematite, magnenite, and mullite, as illustrated in Fig. 10, and the occurrence of hematite was due to the iron ore in the aggregates of FSCs. In addition, the quartz, hematite, and mullite phases were also found in geopolymer foam concrete subjected to elevated temperatures [33]. With the increase of temperature, the peak amplitude of tobermorite decreased gradually, and disappeared at $600{ }^{\circ} \mathrm{C}$. The peak amplitude of calcite nearly did not change in the range of $25-600$ ${ }^{\circ} \mathrm{C}$, while it vanished at $800{ }^{\circ} \mathrm{C}$, which is in line with the observation by Bazant and Kaplan [3]. Moreover, a new crystalline phase, namely, svyatoslavite, was observed at $1000{ }^{\circ} \mathrm{C}$. This new crystalline phase might be conducive to the residual mechanical strengths of FSCs.

\subsection{Thermal analysis}

The effect of temperature on the heat absorption/desorption (DSC) and thermal decomposition behavior (TGA) of the investigated materials, are shown in Fig. 11.

As illustrated in Fig.11a, the DSC patterns of mortar of C1 and C2 mixtures were very similar, 
because the hydration products of the 2 mixtures were the same. The dehydration of FSCs took place at about $100{ }^{\circ} \mathrm{C}$ characterized by loss of evaporable water and part of physically bound water, which is consistent with the observation by Bazant and Kaplan [3]. In the range of $400-600{ }^{\circ} \mathrm{C}$, the decomposition of $\mathrm{CH}$ occurred. This is in line with the reference [3]. At about $580{ }^{\circ} \mathrm{C}$, the crystalline of quartz transformed from $\beta$ - to $\alpha$ - quartz, which is in good agreement with research results of Chase [34]. The decarbonation of calcium carbonate arose at approximately $700{ }^{\circ} \mathrm{C}$. This is consistent with the conclusion that the decomposition of calcium carbonate occurs during $600-$ $900^{\circ} \mathrm{C}$ drawn by Bazant and Kaplan [3]. In general, the dehydration of hydration products (such as $\mathrm{C}-\mathrm{S}-\mathrm{H}, \mathrm{CH}$, and so on) is an ongoing process in the range of $100-850{ }^{\circ} \mathrm{C}$. In a word, the chemical process of FSCs subjected to high temperatures is similar to that of normal concrete (as indicated in literature [3]) exposed to elevated temperatures.

The weight loss of 2 studied FSCs was very close, as shown in Fig.11b, since the mix proportions (Table 4) of them were nearly the same. Between ambient temperature and $150{ }^{\circ} \mathrm{C}$, a quick weight loss was observed in the TGA for the 2 studied FSCs, the result of which is similar to reference [23]. This is due to the loss of evaporable water and part of physically bound water. In the range of $105-$ $700{ }^{\circ} \mathrm{C}$, the weight loss indicated from TGA related to the loss of chemically bound water and the dehydration of hydration products [3]. A dramatic loss in the weight of FSCs was displayed again at $700{ }^{\circ} \mathrm{C}$, which is because of the decarbonation of calcium carbonate. After that temperature, a moderate variation was presented in the TGA. In addition, the weight loss of FSC without PP fibers was invariably lower than that of FSC with PP fibers in the whole range of $25-1000{ }^{\circ} \mathrm{C}$, the result of which accorded fairly well with the mass loss evolution of FSCs (Fig.7).

At $1000^{\circ} \mathrm{C}$, the total weight loss of FSCs was higher than the total mass loss of FSCs, because 
the former was $10.09 \%(\mathrm{C} 1)$ and $9.99 \%(\mathrm{C} 2)$, while the latter was $7.07 \%(\mathrm{C} 1)$ and $7.09 \%(\mathrm{C} 2)$. The

only difference of these 2 experiments is the shapes of the specimens, namely, the specimens used in the thermal analysis experiment were micronized powder (particle size below $80 \mu \mathrm{m}$ ), and the samples utilized in mass loss experiment were massive (about $25 \times 25 \times 25 \mathrm{~mm}$ ). In essence, however, these 2 experiments were the same. Maybe that was because when the micronized specimens were ground, they absorbed moisture in the air.

\section{Conclusions}

This investigation concerns the behavior of FSCs at elevated temperatures. The mechanical and

404

405 physicochemical properties of FSCs were studied at 25, 200, 400, 600, 800, and $1000{ }^{\circ} \mathrm{C}$, and the relationships between strengths and UPV for FSCs were obtained. The main conclusions drawn in this study are as follows:

1) The addition of PP fibers can prevent FSC from spalling, and its spalling mechanisms is unlike those of NSC, HSC, and SCC. The spalling mechanism of FSC may be due to thermal damage, inner expansion force of closed voids, and incompatible deformation between aggregates and cement paste.

2) The compressive strength of FSC with and without PP fibers decreases continually with the increase of temperature. The residual compressive strengths of FSC without fibers are higher than those of FSC with fibers during $25-400{ }^{\circ} \mathrm{C}$, while a contrary tendency is presented in $600-1000{ }^{\circ} \mathrm{C}$.

3) With temperature increasing, the residual splitting tensile strength of FSCs is monotonically decreased. In the whole range of $25-1000{ }^{\circ} \mathrm{C}$, the residual splitting tensile strengths of FSC without PP fibers are lower than those of FSC with PP fibers. 
4) The critical temperature range of FSCs is $400-600{ }^{\circ} \mathrm{C}$, in which their compressive and splitting tensile strength decrease drastically. And the elevated temperatures have a more severe effect on the splitting tensile strength of FSCs than that of compressive strength.

5) The UPV of FSCs decreases continually with the increase of temperature, and the UPV of FSC without PP fibers is always higher than that of FSC with PP fibers in the whole range of $25-$ $1000^{\circ} \mathrm{C}$.

6) The compressive strength - UPV and splitting tensile strength - UPV relationships are Weibull distribution and exponential form, respectively. In practice, the established models can provide a convenient method to assess concrete or structural damage in terms of strengths.

7) The evolution of mass loss as a function of temperature is very close for the 2 studied FSCs, and the mass loss of them was nearly the same with a magnitude of $7.07 \%$ (C1) and $7.09 \%$ (C2) at $1000^{\circ} \mathrm{C}$.

8) A monotonous increase of porosity for FSC with and without PP fibers is observed with temperature increasing. The porosity of FSC without PP fibers is lower than that of FSC with PP fibers in the whole range of $25-1000^{\circ} \mathrm{C}$. Compared to unheated $\mathrm{FSCs}$, the porosity values were more than trebled after exposure to $1000^{\circ} \mathrm{C}$.

9) Svyatoslavite that is a new crystalline phase is observed at $1000{ }^{\circ} \mathrm{C}$. This new crystalline phase may be conducive to the residual mechanical strengths of FSCs.

10) At $1000^{\circ} \mathrm{C}$, the total weight loss of FSCs is higher than the total mass loss of FSCs, because the former is $10.09 \%(\mathrm{C} 1)$ and $9.99 \%(\mathrm{C} 2)$, while the latter is $7.07 \%(\mathrm{C} 1)$ and $7.09 \%(\mathrm{C} 2)$. Maybe that is because when the micronized specimens are ground, they absorb moisture in the air.

\section{Acknowledgments}


442 Transformation of Major Scientific and Technological Achievements of Jiangsu Province Funded 443 Projects (No. 85120000220), which are gratefully appreciated.

\section{$444 \quad$ References}

445 [1] R.J.M. Konings, T.R. Allen, R.E. Stoller, S. Yamanaka, Comprehensive nuclear materials, $446 \quad$ Elsevier, Amsterdam, 2012.

447

[2] O. Bahr, P. Schaumann, B. Bollen, et al, Young's modulus and Poisson's ratio of concrete at high temperatures: Experimental investigations, Mater. Des. 45 (2013) 421-429.

[3] Z.P. Bazant, M.F. Kaplan, Concrete at High Temperatures: Materials Properties and Mathematical Models, Longman, London, 1996.

[4] H.L. Malhotra, Effect of temperature on compressive strength of concrete, Mag. Concr. Res. $8(23)(1956) 85-94$.

[5] M.Y.L. Chew, The assessment of fire damaged concrete, Build. Environ. 28(1) (1993) 97-102.

[6] L.T. Phan, N.J. Carino, Effects of test conditions and mixture proportions on behaviour of high-strength concrete exposed to high temperatures, ACI Mater. J. 99(1) (2002) 54-66.

[7] C.S. Poon, Z. Shui, L. Lam, Compressive behavior of fiber reinforced high-performance concrete subjected to elevated temperatures, Cem. Concr. Res. 34 (2004) 2215-2222.

[8] A. Behnood, M. Ghandehari, Comparison of compressive and splitting tensile strength of high-strength concrete with and without polypropylene fibers heated to high temperatures, Fire Saf. J. 44 (2009) 1015-1022.

[9] J. Xiao, H. Falkner, On residual strength of high-strength concrete with and without 
polypropylene fibers at elevated temperatures, Fire Saf. J. 41(2) (2006) 115-121.

463

464

465

466

467

468

469

470

471

472

473

474

475

476

477

478

479

480

481

482

483

[10] S.P. Shah, A.H. Ahmed, High Performance Concrete: Properties and Applications, McGraw-Hill, New York, 1994.

[11] G. Peng, W. Yang, J. Zhao, et al, Explosive spalling and residual mechanical properties of fiber-toughened high-performance concrete subjected to high temperatures, Cem. Concr. Res. 36 (2006) 723-727.

[12] A.N. Noumowe, R. Siddique, G. Debicki, Permeability of high-performance concrete subjected to elevated temperature $\left(600^{\circ} \mathrm{C}\right)$, Constr. Build. Mater. 23 (2009) 1855-1861.

[13] P. Pliya, A-L. Beaucour, A. Noumowe, Contribution of cocktail of polypropylene and steel fibres in improving the behaviour of high strength concrete subjected to high temperature, Constr. Build. Mater. 25 (2011) 1926-1934.

[14] M.J. Heap, Y. Lavallee, A. Laumann, et al, The influence of thermal-stressing (up to $1000{ }^{\circ} \mathrm{C}$ ) on the physical, mechanical, and chemical properties of siliceous-aggregate, high-strength concrete, Constr. Build. Mater. 42 (2013) 248-265.

[15] M. Ozawa, H. Morimoto, Effects of various fibres on high-temperature spalling in high-performance concrete, Constr. Build. Mater. 71 (2014) 83-92.

[16] C. Castillo, A.J. Durrani, Effect of transient high temperature on high-strength concrete, ACI Mater. J. 87(1) (1990) 47-53.

[17] L.T. Phan, N.J. Carino, Effects of test conditions and mixture proportions on behaviour of high-strength concrete exposed to high temperatures, ACI Mater. J. 99(1) (2002) 54-66.

[18] F.J. Ulm, O. Coussy, Z.P. Bazant, The chunnel fire: chemoplastic softening in rapidly heated concrete, J. Eng. Mech. 125(3) (1999) 272-282. 
[19] R. Jansson, L. Bostrom, Factors influencing fire spalling of self compacting concrete, Mater. Struct. 46 (2013) 1683-1694.

[20] P. Kalifa, G. Chene, C. Galle, High-temperature behaviour of HPC with polypropylene fibres: from spalling to microstructure, Cem. Concr. Res. 31 (2001) 1487-1499.

[21] D.P. Bentz, Fibers, percolation, and spalling of high-performance concrete, ACI Mater. J. 97 (2000) 351-359.

[22] X. Liu, G. Ye, D-G. Schutter, et al, On the mechanism of polypropylene fibres in preventing fire spalling in self-compacting and high-performance cement paste, Cem. Concr. Res. 38 (2008) 487-499.

[23] G. Ye, X. Liu, D-G. Schutter, et al, Phase distribution and microstructural changes of self-compacting cement paste at elevated temperature, Cem. Concr. Res. 37 (2007) 978-987.

[24] M. Uysal, Self-compacting concrete incorporating filler additives: Performance at high temperatures, Constr. Build. Mater. 26 (2012) 701-706.

[25] H. Fares, A. Noumowe, S. Remond, Self-consolidating concrete subjected to high temperature mechanical and physicochemical properties, Cem. Concr. Res. 39 (2009) 1230-1238.

[26] Z. Pan, J.G. Sanjayan, F. Collins, Effect of transient creep on compressive strength of geopolymer concrete for elevated temperature exposure, Cem. Concr. Res. 56 (2014) 182-189.

[27] H. Chu, J. Chen, The experimental study on the correlation of resistivity and damage for conductive concrete, Cem. Concr. Compos. 67 (2016) 12-19.

[28] V.K.R. Kodur, F. Cheng, T. Wang, et al, Effect of strength and fiber reinforcement on fire resistance of high-strength concrete columns, ASCE J. Struct. Eng. 129(2) (2003) 253-259.

[29] S.P. Shah, Do fibers increase the tensile strength of cement-based matrixes? ACI Mater. J. 88(6) 
507 [30] P. Kalifa, F-D. Menneteau, D. Quenard, Spalling and pore pressure in HPC at high 508 temperatures, Cem. Concr. Res. 30 (2000) 1915-1927.

509 [31] H. Chu, J. Jiang, W. Sun, et al, Thermal behavior of siliceous and ferro-siliceous sacrificial $510 \quad$ concrete subjected to elevated temperatures, Mater. Des. 95 (2016) 470-480.

511 [32] T. Sevon, C. Journeau, L. Ferry, VULCANO VB-U7 experiment on interaction between oxidic 512 corium and hematite-containing concrete, Ann. Nucl. Energy. 59 (2013) 224-229.

513 [33] Z. Zhang, J.L. Provis, A. Reid, et al, Mechanical, thermal insulation, thermal resistance and 514 acoustic absorption properties of geopolymer foam concrete, Cem. Concr. Compos. 62 (2015) 97-105.

516 [34] M.W. Chase, NIST-JANAF Thermochemical Tables, J. Phys. Chem. Ref. Data, 1998. 
Table 1 The chemical composition of cement, fly ash, and silica fume (wt.\%)

\begin{tabular}{llll}
\hline Chemical composition & Cement & Fly ash & Silica fume \\
\hline $\mathrm{CaO}$ & 64.70 & 8.38 & 0.77 \\
$\mathrm{SiO}_{2}$ & 20.40 & 47.96 & 96.18 \\
$\mathrm{Al}_{2} \mathrm{O}_{3}$ & 4.70 & 30.46 & 0.96 \\
$\mathrm{Fe}_{2} \mathrm{O}_{3}$ & 3.38 & 5.91 & 0.85 \\
$\mathrm{MgO}$ & 0.87 & 2.60 & 0.74 \\
$\mathrm{SO}_{3}$ & 1.88 & 1.32 & 0.50 \\
$\mathrm{~K}_{2} \mathrm{O}$ & 0.83 & 1.61 & \\
$\mathrm{Na}_{2} \mathrm{O}$ & & & \\
$\mathrm{Loss}$ & 3.24 & & \\
\hline
\end{tabular}


Table 2 The particle size distribution of the aggregates (wt.\%)

\begin{tabular}{lcccccc}
\hline Particle size (mm) & $0-0.15$ & $0.15-0.30$ & $0.30-0.63$ & $0.63-2.36$ & $2.36-4.75$ & $4.75-8.00$ \\
\hline Quartz & 6.30 & 7.60 & 13.50 & 14.60 & 11.50 & 46.50 \\
Iron ore & 5.20 & 7.10 & 12.70 & 39.00 & 17.80 & 18.20 \\
\hline
\end{tabular}


Table 3 Characteristics of PP fiber

\begin{tabular}{llllll}
\hline Length & Diameter & Density & Melting temperature & Burning temperature & Elastic modulus \\
$(\mathrm{mm})$ & $(\mu \mathrm{m})$ & $\left(\mathrm{kg} / \mathrm{m}^{3}\right)$ & $\left({ }^{\mathrm{o}} \mathrm{C}\right)$ & $\left({ }^{\circ} \mathrm{C}\right)$ & $(\mathrm{MPa})$ \\
\hline 12 & 18 & 910 & 169 & 590 & $>3500$ \\
\hline
\end{tabular}


Table 4 Mix proportions of FSCs $\left(\mathrm{kg} / \mathrm{m}^{3}\right)$

\begin{tabular}{lllllllll}
\hline Mix & Cement & Fly ash & Silica fume & Quartz & Iron ore & Water & Superplasticizer & PP fiber \\
\hline C1 & 388 & 135 & 20 & 1060 & 980 & 181 & 7.60 & 0 \\
C2 & 388 & 135 & 20 & 1060 & 980 & 181 & 7.60 & 1.20 \\
\hline
\end{tabular}


Table 5 The relative compressive strength and relative splitting tensile strength of FSCs at different

\begin{tabular}{|c|c|c|c|c|c|c|}
\hline Mechanical strength & Mix & $200^{\circ} \mathrm{C}$ & $400^{\circ} \mathrm{C}$ & $600{ }^{\circ} \mathrm{C}$ & $800^{\circ} \mathrm{C}$ & $1000^{\circ} \mathrm{C}$ \\
\hline Relative residual & $\mathrm{C} 1$ & 88.33 & 84.10 & 37.35 & 26.72 & 14.61 \\
\hline compressive strength & $\mathrm{C} 2$ & 86.77 & 68.87 & 44.98 & 31.30 & 15.43 \\
\hline Relative residual & $\mathrm{C} 1$ & 89.52 & 52.49 & 27.43 & 17.77 & 12.74 \\
\hline splitting tensile strength & $\mathrm{C} 2$ & 84.75 & 53.93 & 28.84 & 19.33 & 13.93 \\
\hline
\end{tabular}


Table 6 The chemical and elemental compositions of mortar of C2 mixture (wt.\%)

\begin{tabular}{|c|c|c|c|}
\hline Chemical composition & Content & Elemental composition & Content \\
\hline $\mathrm{Na}_{2} \mathrm{O}$ & 2.90 & $\mathrm{Na}$ & 2.90 \\
\hline $\mathrm{MgO}$ & 1.94 & $\mathrm{Mg}$ & 1.64 \\
\hline $\mathrm{Al}_{2} \mathrm{O}_{3}$ & 9.98 & $\mathrm{Al}$ & 7.63 \\
\hline $\mathrm{SiO}_{2}$ & 44.20 & $\mathrm{Si}$ & 31.76 \\
\hline $\mathrm{P}_{2} \mathrm{O}_{5}$ & 3.37 & $\mathrm{P}$ & 2.53 \\
\hline $\mathrm{SO}_{3}$ & 1.90 & $\mathrm{~S}$ & 1.34 \\
\hline $\mathrm{CaO}$ & 20.73 & $\mathrm{Ca}$ & 28.41 \\
\hline $\mathrm{K}_{2} \mathrm{O}$ & 0.45 & $\mathrm{~K}$ & 0.69 \\
\hline $\mathrm{Cr}$ & 0.01 & $\mathrm{Cr}$ & 0.03 \\
\hline $\mathrm{V}_{2} \mathrm{O}_{5}$ & 0.01 & $\mathrm{~V}$ & 0.02 \\
\hline $\mathrm{TiO}_{2}$ & 0.24 & $\mathrm{Ti}$ & 0.30 \\
\hline $\mathrm{Cl}$ & 0.15 & $\mathrm{Cl}$ & 0.27 \\
\hline $\mathrm{Fe}_{2} \mathrm{O}_{3}$ & 14.08 & $\mathrm{Fe}$ & 22.37 \\
\hline $\mathrm{MnO}$ & 0.08 & $\mathrm{Mn}$ & 0.13 \\
\hline
\end{tabular}


Click here to download Figure: Figures.docx

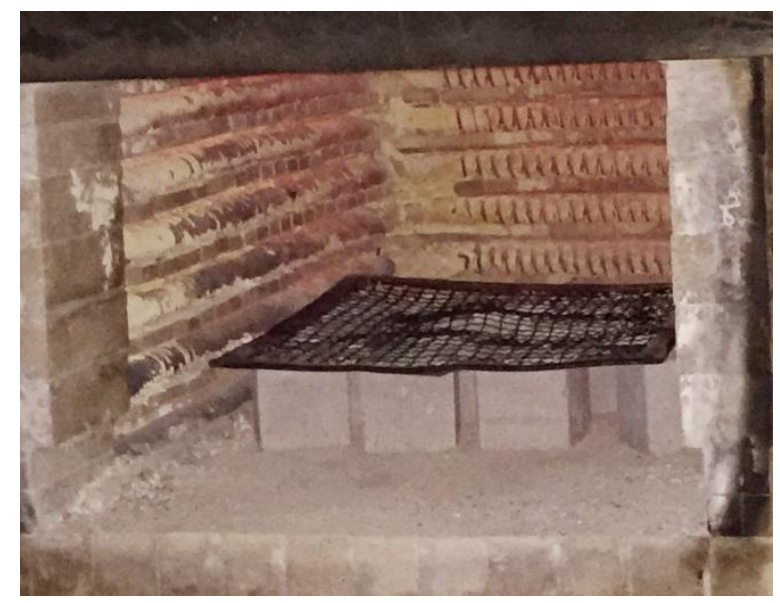

Fig. 1. The layout of specimens in the furnace 

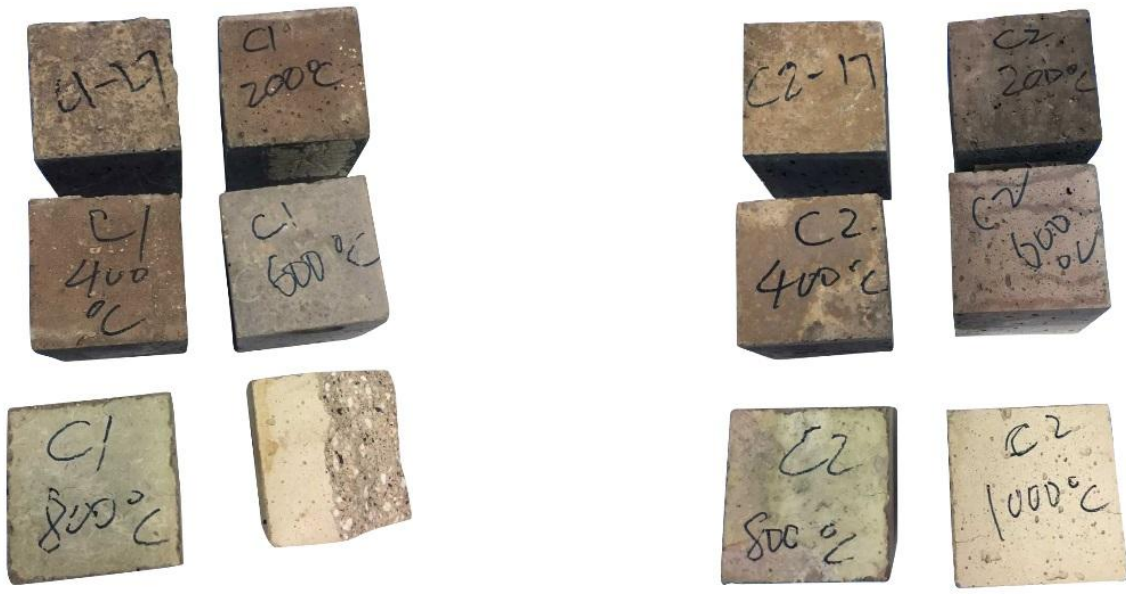

Fig. 2. Specimens (partial) before and after high temperatures treatment. 


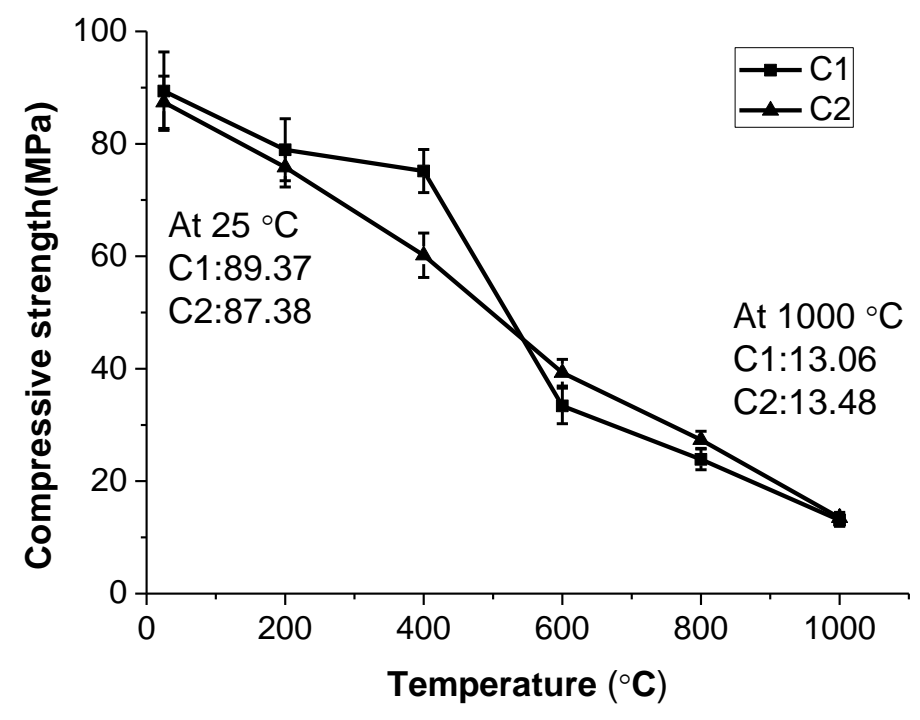

(a)

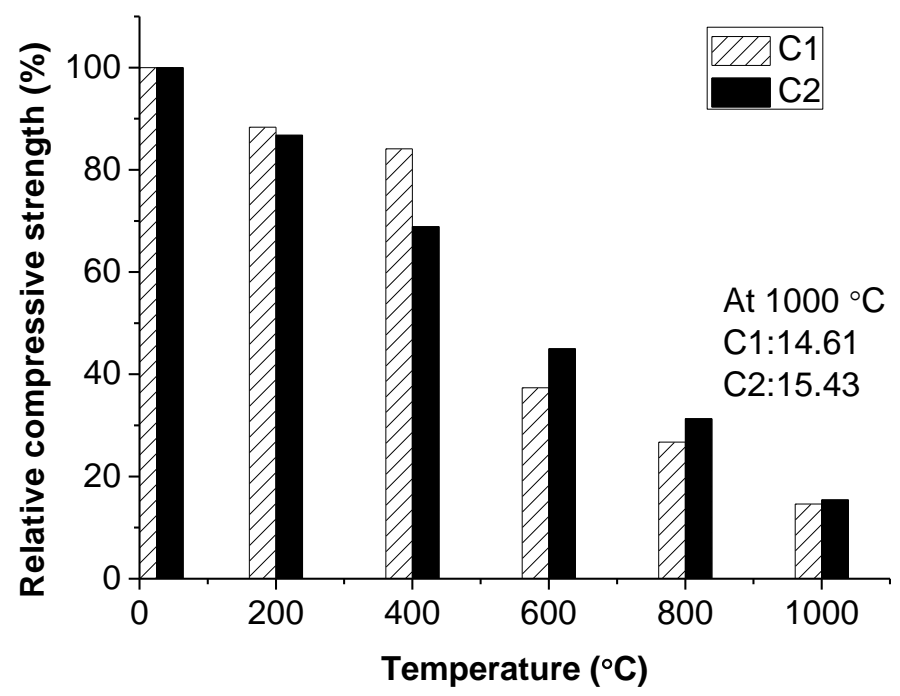

(b)

Fig. 3. The strength of FSCs at ambient and after heating to high temperatures: (a) residual compressive strength and (b) relative residual compressive strength (compared to strength at $25^{\circ} \mathrm{C}$ ) 


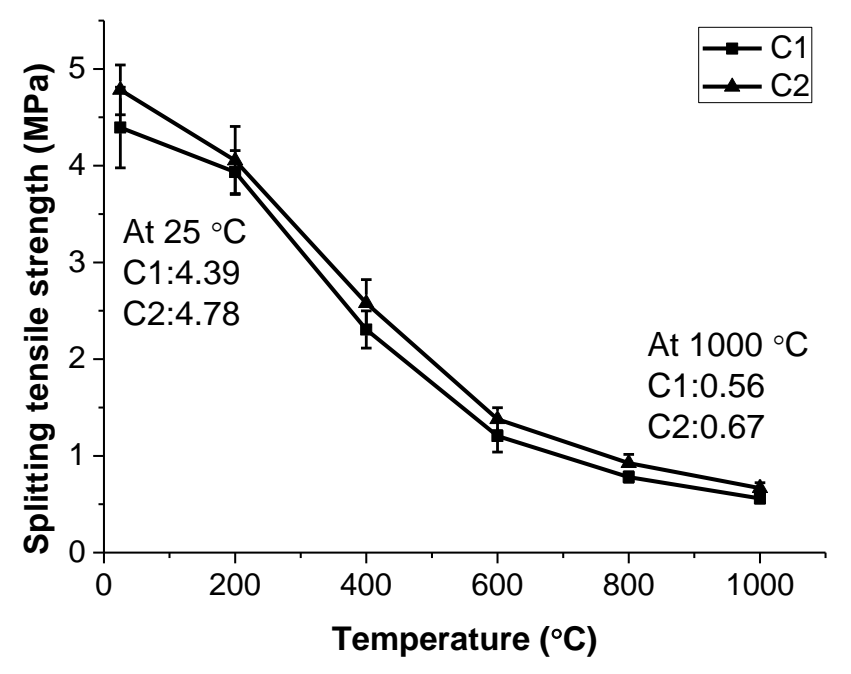

(a)

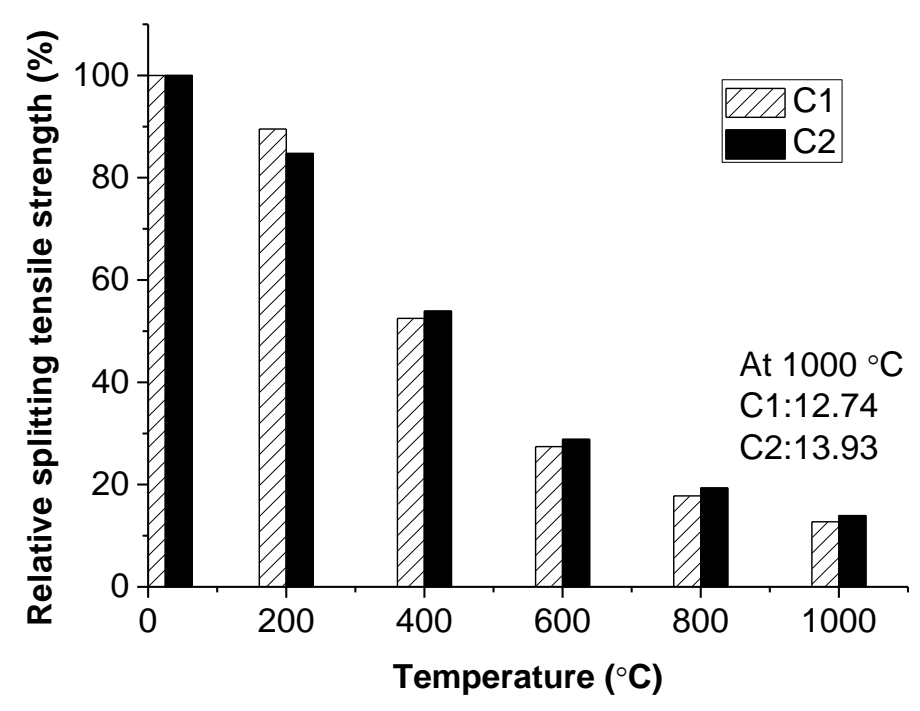

(b)

Fig. 4. The strength of FSCs at ambient and after heating to high temperatures: (a) residual splitting tensile strength and (b) relative splitting tensile strength (compared to strength at $25^{\circ} \mathrm{C}$ ) 


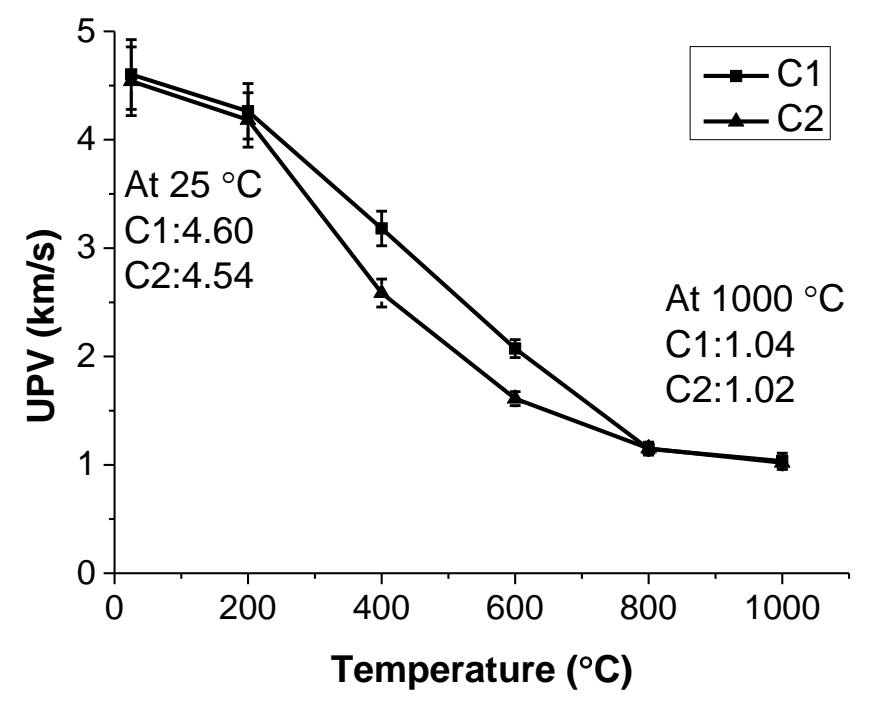

Fig. 5. The UPV of FSCs before and after exposure to high temperatures 


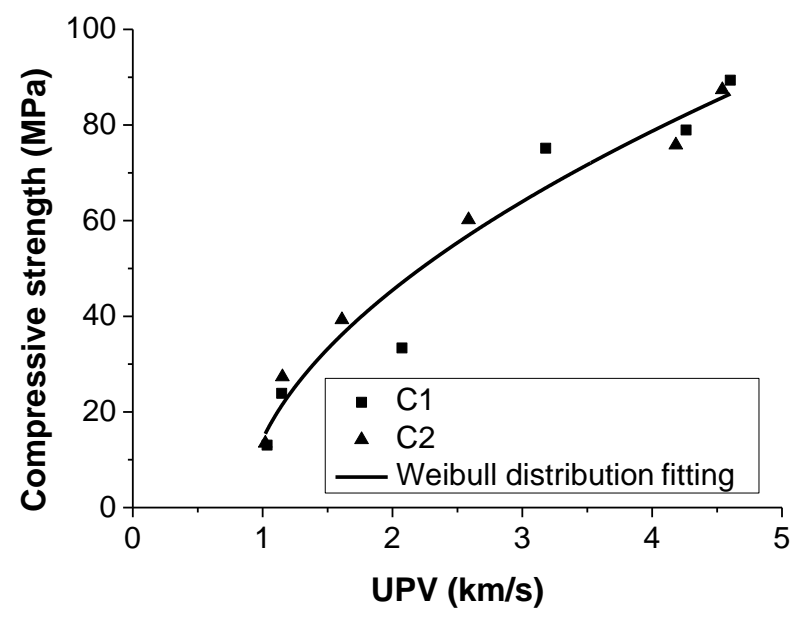

(a)

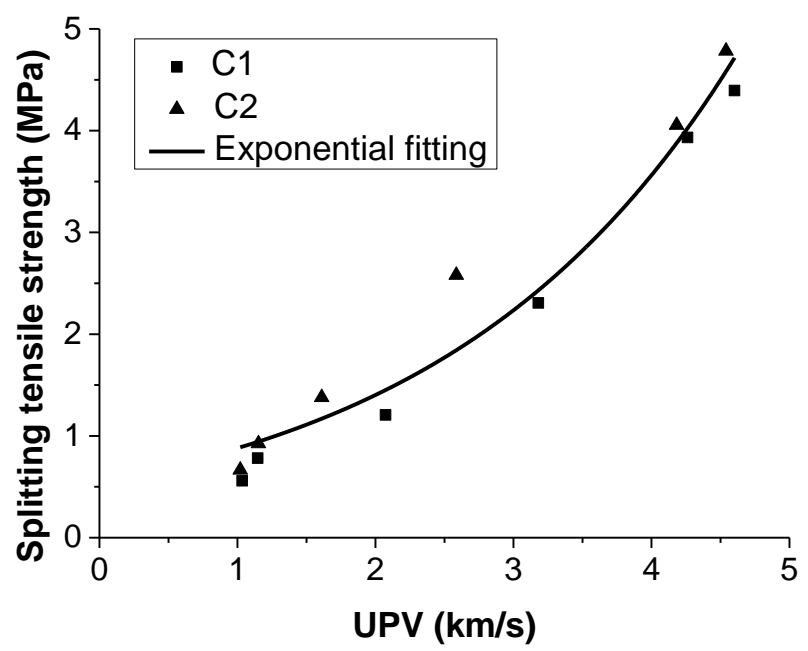

(b)

Fig. 6. The relationships between strengths and UPV for FSCs before and after exposure to high temperatures: (a) compressive strength versus UPV and (b) splitting tensile strength versus UPV 


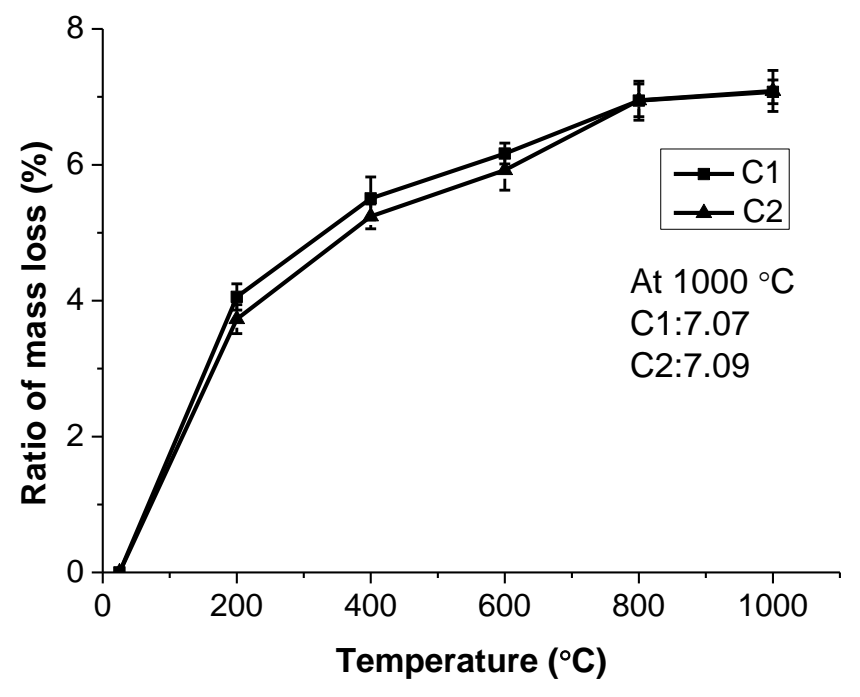

Fig. 7. Ratio of mass loss of FSCs at different temperatures 


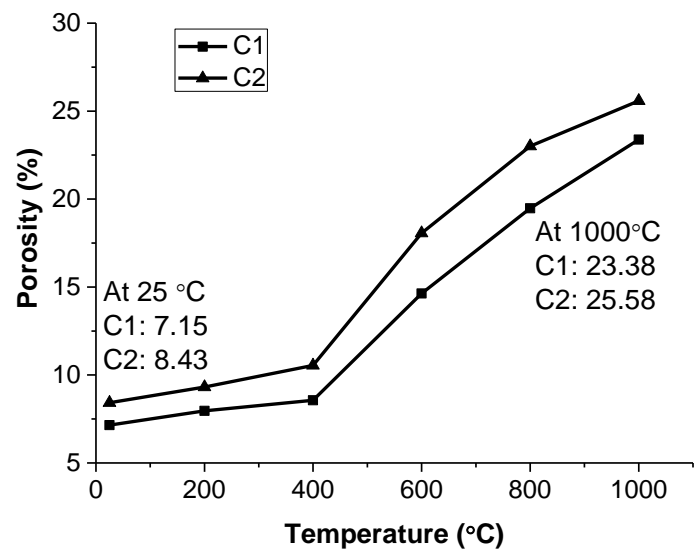

(a)

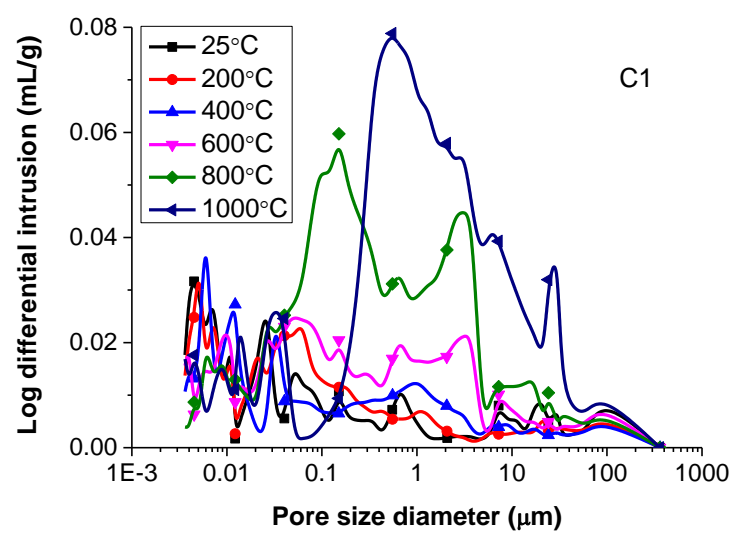

(b)

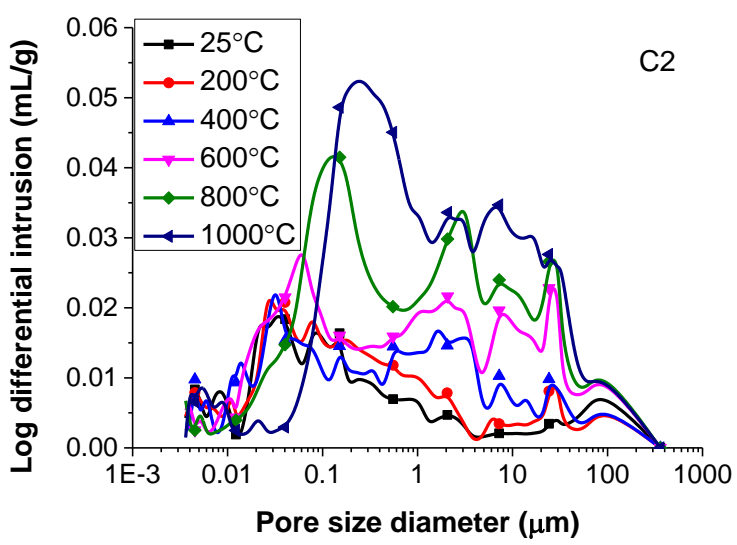

(c)

Fig. 8. The porosity (a) and pore size distribution (b), and (c) of FSCs at ambient $\left(25^{\circ} \mathrm{C}\right)$ and after heating to high temperatures 


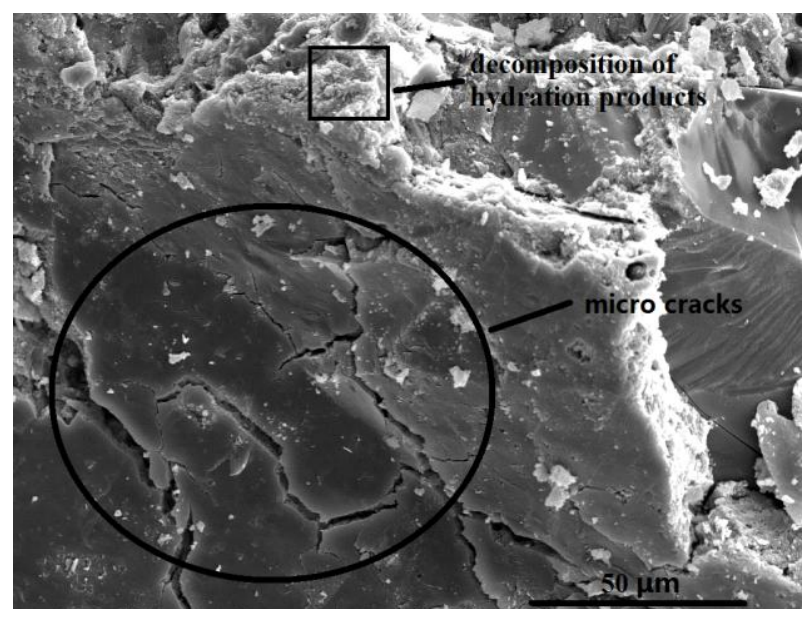

Fig. 9. SEM image of FSC with PP fibers after heating to $600{ }^{\circ} \mathrm{C}$ 


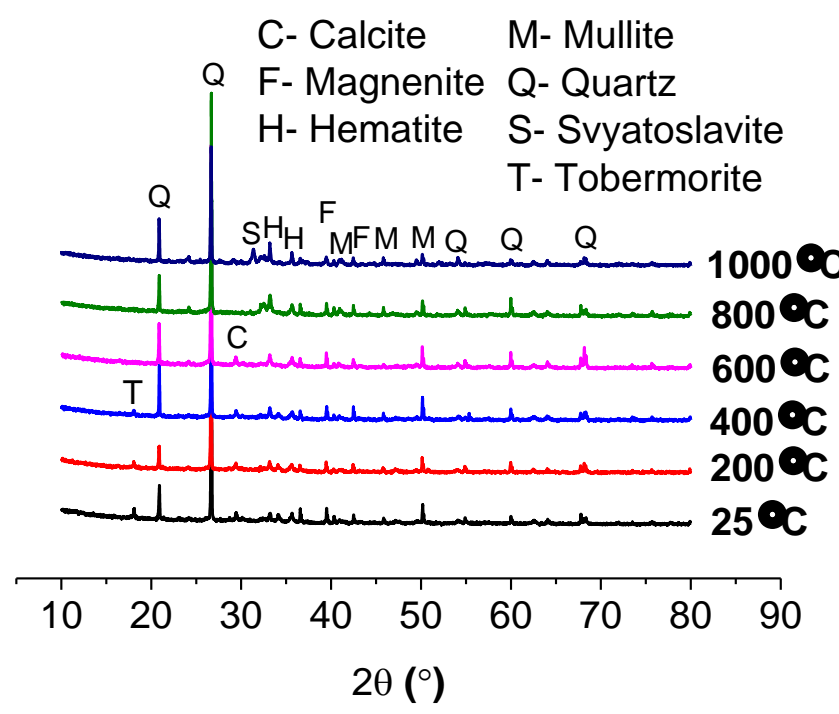

Fig. 10. XRD patterns of FSC with PP fibers before and after high temperatures exposure. Phases identified: calcite, $\mathrm{CaCO}_{3}$; magnetite, $\mathrm{Fe}_{3} \mathrm{O}_{4}$; hematite, $\mathrm{Fe}_{2} \mathrm{O}_{3}$; mullite, $\mathrm{Al}_{4.8} \mathrm{Si}_{1.2} \mathrm{O}_{9.5}$; quartz, $\mathrm{SiO}_{2}$; svyatoslavite, $\mathrm{CaAl}_{2} \mathrm{Si}_{2} \mathrm{O}_{8}$; tobermorite, $\mathrm{Ca}_{5}\left(\mathrm{HSi}_{3} \mathrm{O}_{9}\right)_{2} \cdot 2 \mathrm{H}_{2} \mathrm{O}$. 


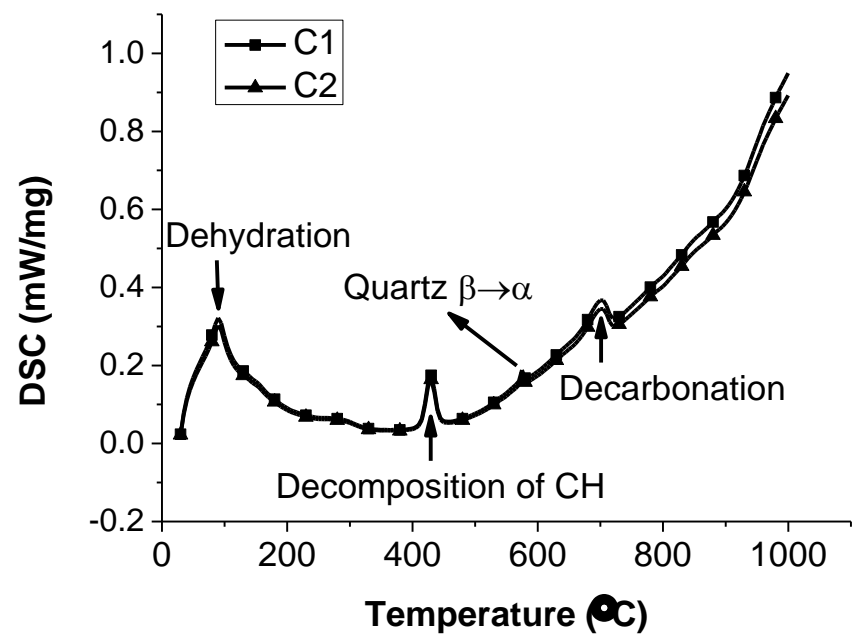

(a)

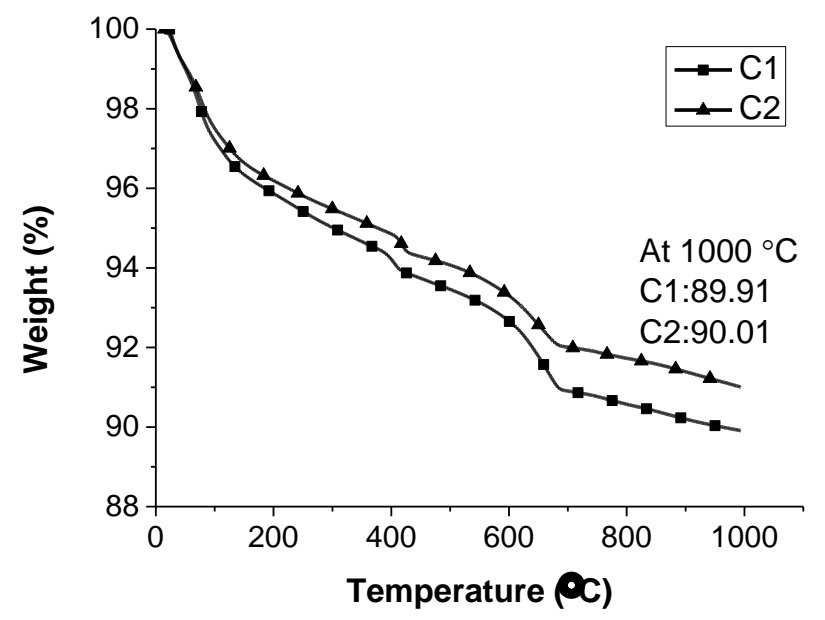

(b)

Fig.11. Thermal analysis of FSCs: (a) DSC spectrums and (b) TGA curves 